plate taken away on the thirty-seventh day. It measured five-eighths by three-eighths of an inch on its inner surface, and the fissure of the external plate extended through its substance.

After this the depression filled in and cicatrised. He complained of occasional giddiness, but was free from hemiplegic and epileptic symptoms. He soon returned to England.

CASE 2.-On Dec. 28th, 1857, J. F-, aged twentysix, received injuries in firing a mortar in Dutch Folly Fort, opposite Canton. His left arm was amputated skilfully by double flaps, at the insertion of the deltoid, an hour after the accident. On the third day he arrived on board the hospital ship at Hong-Kong. Apyrectic; pulse 84 ; no complaint of pain in the stump.

Fourth day.-Apyrectic.

Fifth day.-Stump first dressed. Found the lips adherent, but the anterior flap was red at the margin, and some of its cuticle was vesicated. He was apyrectic. Removed the alternate sutures, and supported the flaps with adhesive plaster. Simple dressings. To take saline mixture.

Sixth day.-Pyrectic; redness and tension at the inner corner of the wound at the exit of the ligatures. Towards evening, leakage of blood, and the redness and tension of the stump increasing.

Seventh day.--Increased tension of stump along the vessels, and oozing of blood. Opened the wound, which was distended with clot and fonl pus, and found the ligatures in situ. Scarified the inflamed integuments, applied wet lint dressing, and a provisional tourniquet. To take dilute sulphuric acid, with tincture of opium. There were frequent small hæmorrhages, and the stump became more tumid and painful, and restless pyrexia increased. At noon I separated the flaps to the full extent, and found their inner surfaces in a sloughy state, with blood oozing from several points, although the ligatures were safe. With the patient under chloroform I applied the only actual cautery I had at hand-a plaster-spreader, heated to redness-to all the bleeding points, and then used the chlorinated soda wash on lint between the flaps.

Eighth day. - He slept; tongue moist; pulse 90 and feeble; no leakage of blood or pus, and the stump less tumid. Ordered, chlorinated soda lotion; brandy mixture; and an anodyne draught as may be necessary. - 6 P.M. After sneezing, a sudden copious flow of blood from stump. Found the sloughing action general and deep; blood oozing from the sloughing parts and jetting from the posterior circumflex artery. I placed a ligature deeply on the circumflex, and, having all the ligatures carefully held aside, I applied very freely the actual cautery, approaching to white heat, on every part of the surface, pushing it firmly and deeply wherever bogginess was felt, and especially so into the pit where the great vessels lay. The gangrene having destroyed the centre of the deltoid and attacked the anterior flap, it was slit in two, and the cautery applied to the free edues. This was effected under chloroform. He was ordered chlorinated soda lotion, and to have brandy, and an anodyne draught if necessary.

Ninth day. - Slept; tongue cleaner; pulse 90, of good force; no further leakage of blood; slight purulent traces Oiled lint was placed between the flaps, and chlorinated soda lotion applied to surface of stump. To have eight ounces of port wine, and brandy mixture $a d$ lib.

Tenth day. -General improvement; pulse 100, bounding; tongue clean; bowels open; stump decreased in size; edges of flaps looking clean; deep sloughs adherent. Continue treatment, and add quinine mixture.

Eleventh day. - Copious discharge of laudable pus, and freedom from pain; tongue moist; pulse 110 and weak. Continue remedies.

Twelfth day.-Eschars detaching without oozing of blood, and stump secreting clean pus frecly; appetite ${ }_{2}^{\prime a i r}$. Omit brandy; give twelve ounces of wine.

Thirteenth day.-Stump granulating healthily.

From that date the stump healed kindly, but more or less quickly according to the state of his system. Through the fourth week he had a sharp attack of constitutional disturbance with diarrhoea, during which the granulations were pale and indolent. As this state subsided, he began to suffer from severe otitis, having from the first complained of deafness in the left ear, which lay towards the mortar when it was fired. It ended in abscess of the middle ear, with destruction of the tympanum. In spite of these drawbacks, however, the stump healed kindly, and the man was sent to England.

London, Sept. 1870.

\section{ON APHASIA.}

BY J. A. THACKER, M. D.,

PROFESSOR OF PSTCHOLOGY AND DISEASES OF THE NERVOTS SYSTEY IN THE CINCINAATI COLLEGE OF MEDICINE AND SURGERT, CINCTYNATI, T.S.

(Concluded from page 430 .)

Now it is evident, if what I have stated be true, that speech is the result of what metaphysicians term the faculty of association-a faculty, if there be such a one, that no one knows anything about, more than that there exists in the human mind a potentiality of associating ideas together, so that one idea may bring up another, and this again another, producing an interminable train, unless something interferes to break the procession. And not only are ideas so associated that the occurrence of some particular one to the mind will call up another, but certain acts or muscular movements are oftentimes associated with certain ideas, so that the former are always suggested by the latter, and in turn suggest them. Of the last-mentioned class of associations (actions with ideas) I could give very many examples, but one or two will suffice. A little reflection on the part of the reader will call to his mind many others. The roar of the wild beast will cause the traveller, resting by the wayside, to start to his feet in preparation for escape, even when he is not exposed to danger, from having been accustomed to flee at the sound; and rapid flight on the part of anyone always suggests to our minds a threatening danger. The physician puts on his hat and seizes his cane, preliminary to setting forth to visit a patient, withoute mploying any mental operation whatever; the idea is formed, and the associated act follows automatically.

Bernard very correctly states, in one of the sentences of his remarks which $X$ have quoted, that, "in the education of the organs of speech there is consequently established between the auditive sensation and the vocal motion a veritable nervous circuit, which connects the two phenomena into a common functional object." To employ language more readily understood, an idea becomes associated with a certain sound proceeding from movements of the muscles of the tongue, larynx, \&c., by means of the organs of hearing, so that when the particular sound occurs the same idea is awakened, and, vice versa, the idea suggests the sound that has been heard to express it. The idea of danger not only tends to call into action the movements of escape, but rapid flight occasions thoughts of peril. So closely interwoven do words and ideas become by long-continued association that they seem to be inseparable, and lead to the error that there cannot be an idea without a word giving utterance to it, or formed in the mind expressing it. "A word is nothing more than the artificial mark of the muscular act of speech into which tine idea is translated, and a name nothing more than a particular word appropriated to mark a certuin idea, so that wher beard or seen it may excite the same idea in our mind, or a similar idea to other minds." "But because its muscular acts," says Dr. Maudsley, "receive a special name-are called speechthey are not special in kind, and have not more a special faculty in the mind than any other definite co-ordinate movement has."

The little child possesses ail the muscles necessary for emitting from the vocal organs a great variety of sounds, and organs of hearing for taking cognisance of them. As its cerebral hemispheres become dereloped, and the in. pressions received are organised into ideas, associations, first of the simplest character, begin to be formed, and by and-by it learns from its educators to conuect certain ideas with particular sounds, so that when the latter are heard the former come into the mind, and rice $i e \cdot s \hat{t}$. First it associates the word "Namma "with its mother, and when it is able to lisp it itself by induced efforts at imitation it has taken its first step in lan ruage. It will thus be perceived that "in the education of the organs of speecin there is 
consequently established between the auditive sensation and the vocal motion a veritable nervous circuit, which connects the two phenomena in a common functional object."

Says Bernard, in the address before alluded to, "It has been said that silence is eloquent; ay, for those who cannot speak, and for those who, being initiated to all the emotions of the heart, feel that there then takes place something in us which words cannot express!"

Granted that the views which $I$ have set forth are correct as to the mechanism of speech, what condition has been brought about in an individual suffering from aphasia? It seems to me that the most philosophical mode of accounting for the affection is to ascribe it to a destruction of the associations, which had been formed, of ideas and the various muscular movements which produced the sounds from the organs of speech representing them; in other words, the "ideo-motor intuition" no longer takes place when a thought enters the mind, and, therefore, there is no exciting current, as it were, conveyed from the sensorium commune through the motor nerves to the muscles of the larynx, tongue, \&c. As I have said, an individual, when learning to speak, is taught to associate his ideas with particular sounds, and, possessing the mechanism in himself of forming the same sounds, an "ideo-motor intuition" or impulse results, which, when excited, enables him to make use of the words which he has connected with particular ideas. But certain changes having taken place in the structure of the brain tissue, not at a particular point, but generally throughout the nerve cells, the accustomed associations no longer occur, and the loss of speech or written language, or both, is the result-both alike being dependent upon ideomotor intuitions from associating ideas and muscular movements, and follow upon the action of their own set of muscles, as is the way with intelligent signs and demonstrations of every kind. Every mode of giving external expression to what is passing in the mind is a language so far as it goes, and, when employed, results upon associating the idea and the particular action constituting the "ideo-motor intuition " of that language.

Many illustrations could be given of the obliteration, by cerebral changes, of the so-called faculty of association in other instances than we see in associating ideas with particular movements of the muscles called in action in speech. In old age, the power of associating ideas together, so that one may call up another, becomes very much weakened, and is a great hindrance in carrying on mental processes of any kind. In the young it is active, and contributes largely to the ready remembering of facts; but as the vesicular matter of the cerebrum becomes modified by time-as the mind, as suggested by Herbert Spencer, proceeds more and more from the indefinite to the definite, unless it attain a definiteness inconsistent with its existence-it gradually fails and oftentimes disappears entirely. Again, the association which exists in the love of an individual of one sex for another of the opposite not unfrequently is obliterated either by traumatic injury or idiopathic disease; so also may the affection of parent for child be destroyed by the same causes, and even sometimes supplanted by hatred. True there are instinctive associations, but their character is not changed because they have not been acquired. When they have been acquired a potentiality existed, which is the foundation of nearly all of men's associations, and which constitutes a marked difference between them and the lower animals, in which nearly all are instinctive.

Dr. Maudsley suggests, among other explanations as the cause of aphasia, the loss of the muscular sense in the organs of speech; but as this sense has certainly no distinct existence like those of sight, taste, and smell, \&c., the proposed explanation does not appear to me satisfactory. The "muscular sense" depends upon that of touch, and while it cannot exist without it, it is difficult to conceive of its being absent while the former is present. I do not know that it has ever been shown that anæsthesia of the organs of speech is a constant phenomenon. The muscular sense, too, if I rightly understand it, simply means muscular resistance, and how muscular resistance is involved in speech $I$ do not fully comprehend. Surely in the case of amnesia of written language, which is often a feature in aphasia, there cannot be alleged a failure of the muscular sense.

Gall, as is well known, in 1809, first advanced the proposition that there is a faculty of language, and located it in the anterior lobes of the brain. In 1861, Prof. Paul Broca went further, and pointed out as its seat the third frontal convolution of the left hemisphere. In proof of his view he presented to the Société Anatomique, of Paris, two specimens obtained by post-mortem from two aphasies, and afterwards during the year other corroborative evidence from autopsies. Bouillaud and other distinguished Frenchmen gave their assent to this notion, and at different times it has been discussed, for and against, in the Societies of France, with much spirit, sometimes even approaching almost to violence. Further research, however, has now proved it beyond doubt to be incorrect; for examination of the brain after death has shown the particular convolution intact in persons aphasic during life; and, again, not only it, but the whole anterior portion of the left hemisphere destroyed in those whose speech had not been affected. It seems to methat our present knowledge of the anatomy and physiology of the nervous system is sufficient to disprove Gall's theory, and, as a consequence, that of Broca, without the support of autopsies; for the reason, as Dr. Maudsley points out in THE LANCET, that if there is a centre of anguage in the brain, all other portions of the encephalon concerned in the formation of ideas would have to be connected with it in order that their ideas might find expression in speech, which we know is not the fact. In fact, it would be necessary for it to be the centre of two sets of fibres, one bringing impressions of ideas from other parts of the cerebral hemispheres, and another connecting it with the organs of speech.

Of course, I would not attempt to explain the mechanism of the association of ideas with one another, and with particular muscular movements, or anything in regard to its essential nature. Mr. Mansel, in his very philosophical work upon the subject, proves that there is necessarily a limit to religious thought; and we may very properly consider that there is also a limit to physiological thought. It is a property which is as yet beyond our ken, and may always remain so. We are very well aware of the fact that in the physical world particular particles of matter, under favourable circumstances, cohere, but of the nature of the attraction of cohesion we are ignorant; also that, under certain conditions, a plant, with a nicety of discrimination truly wonderful, selects from the atmosphere about it and from the soil in which it is planted the elements favourable to its nutrition, rejecting all others; but how it does it-the subtleties of its nature which enables it-we know nothing. These are properties which we ought to be able to recognise, even if we do not understand their modi opesandi and know that they are properties.

A distinguished writer states, and it seems to me very correctly, that conclusions respecting aphasia have been drawn too entirely from pathological observations, without regard to the important bearing which language in its physiological and intellectnal aspect has on the question to be resolved. If we ever expect to understand the lesions of the brain which bring about a loss of speech, we must first be in possession of a correct philosophy of speech, otherwise, even if we know that this or that injury will result in aphasia, the information will not be of much value. If an individual knows nothing about the philosophical principles involved in the movements of a steam-engine, his knowledge that a particular accident to the machinery has resulted in a stoppage of its working would be of little value, and do but little in qualifying him for its repair. The most important lnowledge to be in possession of is not the fact that a certain lesion has produced a particular result, but what principles underlie the conditions which have been destroyed. "Had the subjective method been properly used, and the psychological relations of language duly considered," says one of the authors from whom I have quoted, " it may be questioned whether the theory that a part of the left frontal convoiution was the seat of articulate language would ever have been promulgated so hastily and, I may add, received so rashly. To my mind there has been nothing like it since Descartes located the soul in the pineal gland."”

Dr. Bucknill says : "How any combination of cells can be attended by processes of thought [and in them we may include the phenomena of association], is to us inconceivable; but it is not more inconceivable than that similar combinations should result in the phenomena of life, or that a combination of atoms should result in the more- 
ments of the solar system." Go as far with solution as we may, there still will remain a problem unsolved, for the chain is, of necessity, infinite. When we have gotten so far in elucidation as to demonstrate that a particular phenomenon is essentiul to any manifestation, a property of it, as in the case of gravitation and matter, we have proceeded as far in our investigations as we can.

There are quite often other phenomena to be observed in aphasia besides amnesia of articulate and written language, but as they may be regarded as more or less incidental, I have confined myself to the treatment of the affection in what may be termed its pure form.

\section{ON}

\section{THE APPLICATION OF PRESSURE TO THE UTERUS IN CASES OF LINGERING LABOUR.}

BY W. S. PLAYFAIR, M.D., F.R.C.P., ASSISTAYTT OBSTETRIO PHYSICTAN TO KING'S COLLEGE HOSPITAL,

1XD SENIOR PHYSICIAN TO THE EVELINA HOSPITAI FOR SICK CHILDREN.

IN 1856 Von Ritgen suggested the employment of external pressure on the uterus as an adjuvant in cases of powerless labour. In 1867 Kristeller carried the suggestion into practice, and published a number of cases in which he had found it of use.

The object was, to push the presenting part through the pelvic canal in cases in which the forceps would otherwise be required to pull it through; to apply, in fact, a vis a tergo instead of a vis a fronte.

This proposal has met with but little attention in this country; and the only author who, as far as I know, refers to it, is Dr. Barnes, in his recent admirable work. He says with regard to it: "This resource, then, should not be lost sight of. In certain cases it may obviate the necessity of using the forceps; or it may stand you in good stead when instruments are not at hand."

It is certain that the advantages to be derived from external pressure are not yet widely known or recognised; and as I have now received very material assistance from it in many cases of lingering and powerless labour, I believe it may not be without interest to state briefly the result of my experience on this point, especially as I do not know of any published cases in this country in which its use has been described.

The class of case in which external pressure is likely to prove serviceable is of very frequent occurrence-viz., in which the presentation is natural, and the pelvis roomy, but in which delivery is retarded simply from deficiency or absence of uterine contraction. These are the cases in which resort to the forceps is so often essential, in which the head has passed well into the pelvis, possibly descended as low as the perineum, and in which apparently but one or two gond pains are required to complete the delivery.

Firm pressure, applied under such circumstances, may act in two ways: First, and most commonly, it may merely stimulate the sluggish uterus to increased exertion, just as firm pressure after delivery will cause a relaxed uterus to contract. In this way, pains that are feeble and ineffective may be rendered strong and useful, and a natural termination may result when artificia! assistance might otherwise be required. I have of late been frequently in the habit of thus stimulating the uterus, and I feel certain that I have in many instances greatly shortened the progress of a labour that threatened to be long and tedious. It is, indeed, often curious to observe how rapidly the pains increase in force and duration, under the stimulation of gentle and steady pressure at the commencement of each pain. The following case may be taken as a good example of the beneficial effect of pressure applied in this way.

-. the mother of several children, about thirty-five years of age. Labour commenced at noon on the 23rd of February, 1868. The pains were at long intervals, feeble, and of short duration. At 3 A.M. on the morning of the 24th the membranes had been ruptured for several hours, and the os was fully dilated. The pains were now more frequent and regular, but they had no effect in causing the head to pass through the brim. It remained partially en. gaged, but always receded in the intervals between the pains. After waiting for some time, it seemed as if the forceps would be required. Von Ritgen's method was now tried. The patient being laid on her back, and the hands being spread out on the sides and fundus of the uterus, firm downward pressure was made in the axis of the brim at the commencement of each pain. 'The good effects of this mancuvre were very striking. The first pain was manifestly increased in strength and duration, and the head was felt to advance decidedly as it was pushed down. The contractions now increased greatly in force, and in about six pains the head was expelled. It was in the third position, and the rotation of the occiput forwards was readily made out as it descended. The child was of immense size, and living. The mother made a good and rapid recovery.

This may be taken as a typical example of the most usual effect of pressure-viz., to stimulate the uterus to increased exertion; and I believe it to be a far more effective and safe agent for this purpose than ergot.

Secondly, it is sometimes possible to push out, as it were, the foetus in the entire absence of uterine pains. I presume that cases suitable for this must be rare, and that, as a rule, extraction by the forceps is to be preferred. Still the following case may be taken as proving the possibility of occasionally effecting delivery in this way.

, aged twenty-five, a lady of great delicacy of constitution, was pregnant of her third child. She had suffered a good deal during gestation, was immensely distended with liquor amnii, and for some months had been almost entirely confined to her sofa. Her labour commenced on the 10th of August, 1870. During most of the day she had feeble pains, and at long intervals. At 10 P.M. the os was only slightly dilated, and the head was felt to be presenting. The pains got somewhat stronger at 3 A.M., and at 4 A.M. the membranes ruptured, an enormous quantity of water being discharged. At 6 A.m. the os was fully dilated, and the head was engaged in the brim in the first position. The pains were now scarcely worthy of the name. At short intervals there was a barely perceptible hardening of the uterus, which disappeared almost as soon as it was felt, and had no appreciable effect on the presenting part. I was informed that ergot had been administered with advantage in a former labour, and I gave her a full dose without any good result. After waiting till 11 A.Mr., I began to despair of any progress. The slight contractions previously felt had disappeared, or nearly so, and I made up my mind to apply the forceps.

The husband, however, objected so strongly to any instrumental interference that I determined to try the effect of pressure, although, in the absence of uterine contractions, I scarcely expected any beneficial results.

Spreading the hands over the uterus in the usual way, I made firm downward pressure at intervals of from five to ten minutes. The effect was more favourable than $I$ had anticipated. With each application of the pressure the head was felt to descend, and in about three-quarters of an hour it was distending the perineum. Now for the first time some slight contraction was felt, and the head was soon expelled. The child was born alive, and the mother made an excellent recovery.

A case of this sort is no doubt quite exceptional, and I should generally prefer under such circumstances to apply the forceps. Still it may serve to illustrate Kristeller's statement that external pressure alone is capable of effecting delivery. It is, however, as an adjuvant in cases of lingering labour, and as a means of stimulating a feebly contracting uterus, that pressure promises to be of service. I need hardly add, by way of caution, that gentle but firm pressure in a proper direction is to be used, and that all rough handling of the uterus is to be avoided. The pressure can be most readily applied with the patient lying on her back, but this is by no means essential, and I have constantly used it in the ordinary position on the side, and without disturbing the patient.

Curzon-street, Mayfair, Aug. $18 \%$.

THE scarlet fever epidemic in London continues unabated, the deaths having been 165,157 , and 167 , in the last three weeks. In the Battersea sub-district this disease has caused no less than 24 out of 55 deaths during the last fortnight. 